\title{
PENGARUH KNOWLEDGE SHARING DAN KEPERCAYAAN TERHADAP KINERJA KARYAWAN PT TUNAS DWIPA MATRA KEPAHIANG
}

\author{
Praningrum" ${ }^{1}$, Febrianto ${ }^{2}$ \\ 1,2)Fakultas Ekonomi dan Bisnis, Universitas Bengkulu, Bengkulu
}

\begin{abstract}
Abstrak $\quad$ Tujuan penelitian ini adalah untuk menganalisis pengaruh knowledge sharing dan kepercayaan terhadap kinerja karyawan di PT Tunas Dwipa Matra Cabang Kepahiang Provinsi Bengkulu. Penelitian ini menggunakan metode survei dengan mendistribusikan kuesioner pada sampel penelitian yang terdiri dari 40 responden yang merupakan staf dan manajer di PT Tunas Dwipa Matra Cabang Kepahiang. Data dianalisis dengan analisis regresi linear berganda menggunakan program SPSS. Hasil penelitian menunjukkan bahwa knowledge sharing dan kepercayaan berpengaruh positif dan signifikan pada kinerja karyawan di PT Tunas Dwipa Matra Cabang Kepahiang. Perusahaan dapat terus meningkatkan aktivitas knowledge sharing karyawan berkenaan dengan prosedur dan pembagian tugas yang jelas yang dilandasi oleh rasa saling percaya demi mencapai kinerja terbaik.
\end{abstract}

Kata Kunci : $\quad$ kepercayaan, kinerja, knowledge sharing

\begin{tabular}{l|l} 
Abstract & $\begin{array}{l}\text { The purpose of this study is to analyze the effect of knowledge sharing and trust on } \\
\text { employee performance at PT Tunas Dwipa Matra Kepahiang, Bengkulu Province. This study } \\
\text { used a survey approach by distributing questionnaires to the research sample that consisted } \\
\text { of } 40 \text { respondents who were the staff and managers at PT Tunas Dwipa Matra Kepahiang. } \\
\text { Data were analyzed by multiple linear regression analysis using SPSS program. Results } \\
\text { showed that knowledge sharing and trust had a positive and significant effect on employee } \\
\text { performance at PT Tunas Dwipa Matra Kepahiang. Thus, the company could improve the } \\
\text { knowledge sharing activities related to the work procedures and clear tasks division among } \\
\text { its employees based on mutual trust to achieve the best performance. }\end{array}$
\end{tabular}

Keywords : $\quad$ knowledge sharing, performance, trust

Fakultas Ekonomi dan Bisnis

Universitas Bengkulu

E-mail: praningrumningrum@gmail.com 


\section{Pendahuluan}

Di dalam sebuah organisasi, pengetahuan merupakan aset yang sangat penting. Melalui pengetahuan, organisasi dapat menjalankan fungsinya secara lebih baik. Setiap individu memiliki pengetahuan dari hasil pengalaman kerjanya. Semakin lama seseorang bekerja maka pengetahuannya dan wawasannya akan pekerjaan semakin bertambah. Pengetahuan yang dimiliki individu akan menjadi aset bagi dirinya sendiri, tidak secara langsung menjadi milik organisasi.

Delphi Group melakukan riset tentang komposisi pengetahuan yang tersimpan yaitu $42 \%$ di pikiran karyawan, 26\% dokumen kertas, $20 \%$ dokumen elektronik, dan $12 \%$ database elektronik. Hal ini menunjukkan bahwa sebagian besar aset pengetahuan tersimpan dalam pikiran seseorang. Jika individu mau berbagi, maka $42 \%$ pengetahuan yang masih berada di pikiran atau otak masing-masing karyawan dapat dibagikan kepada karyawan lain melalui kegiatan berbagi pengetahuan atau knowledge sharing (Setiarso, 2009).

Kegiatan knowledge sharing membawa banyak nilai positif bagi organisasi. Pengetahuan dan wawasan yang dimiliki karyawan akan semakin bertambah, juga sebagai sarana komunikasi antar karyawan agar hubungan interpersonal menjadi erat. Yusup (2012) mengatakan bahwa knowledge sharing merupakan gambaran konsep tentang interaksi berbentuk komunikasi yang terjadi antara dua orang atau lebih guna mengembangkan dan meningkatkan pengetahuan seseorang. Dengan adanya peningkatan pengetahuan, diharapkan terdapat peningkatan kinerja organisasi/perusahaan. Knowledge sharing juga akan menghasilkan pengetahuan baru, inovasi yang dapat meningkatkan kinerja individu dan kinerja oganisasi (Wang, 2006).

Faktor lain yang juga dapat mempengaruhi kinerja karyawan adalah kepercayaan. Hal ini sejalan dengan pernyataan Colquitt (2007) bahwa karyawan akan bekerjasama dengan baik dengan rekan kerjanya apabila fondasi hubungan mereka adalah rasa saling percaya berdasarkan tujuan bersama dan pertemanan yang erat dalam jangka waktu yang lama sehingga nantinya akan berdampak pada peningkatan kinerja.

Melihat pentingnya peran knowledge sharing dan kepercayaan terhadap peningkatan kinerja karyawan, maka penelitian ini bertujuan untuk mengetahui pengaruh knowledge sharing terhadap kinerja, dan pengaruh kepercayaan terhadap kinerja karyawan di PT Tunas Dwipa Matra Kepahiang Provinsi Bengkulu. Perusahaan tersebut adalah sebuah perusahaan yang bergerak dibidang pemasaran sepeda motor merek Honda. Perusahaan ini dipilih dengan alasan bahwa peningkatan kinerja pada perusahaan ini dapat dilakukan jika karyawannya mau melakukan knowledge sharing dan saling percaya satu dengan lainnya.

Beberapa penelitian empiris menemukan bahwa knowledge sharing dapat mempengaruhi kinerja. De Vries et al (2006) menyebutkan bahwa knowledge sharing dapat mempengaruhi kinerja. Chen dan Chen (2011) menyatakan bahwa knowledge sharing sebagai sarana untuk menciptakan pengetahuan baru yang berkontribusi pada peningkatan kinerja karyawan. Memah et al (2017) dalam penelitiannya terhadap kinerja karyawan Kantor Perwakilan Bank Indonesia di Sulawesi Utara menyimpulkan bahwa terdapat pengaruh knowledge sharing terhadap kinerja karyawan Bank Indonesia di Sulawesi Utara. Berdasarkan beberapa hasil penelitian empiris tersebut, maka diajukan hipotesis pertama penelitian ini sebagai berikut:

$\mathrm{H}_{1}$ : Knowledge sharing berpengaruh terhadap kinerja karyawan PT Tunas Dwipa Matra Kepahiang

Menurut de Jong et al (2016), kinerja tim kerja dipengaruhi oleh kepercayaan, sejalan dengan pendapat Brown et al (2015), yang juga menyatakan bahwa kepercayaan pegawai di tempat kerja berpengaruh terhadap kinerja pegawai. Kepercayaan merupakan kunci bagi kinerja karyawan karena kepercayaan memungkinkan kerjasama yang bersifat sukarela. Kepercayaan membantu pengembangan dan 
pemeliharaan internal diantara berbagai kelompok dalam perusahaan yang memungkinkan terjalinnya kerjasama yang baik diantara anggota perusahaan (Mathis dan Jackson, 2006). Berdasarkan hasil penelitian terdahulu, maka hipotesis kedua yang diajukan dalam penelitian ini adalah:

$\mathrm{H}_{2}$ : Kepercayaan berpengaruh terhadap kinerja karyawan PT Tunas Dwipa Matra Kepahiang.

Berdasarkan latar belakang, tujuan, serta hipotesis penelitian yang telah diuraikan sebelumnya, maka disusunlah suatu model penelitian. Model ini berdasarkan pada teori knowledge sharing dari Hooff dan de Ridder (2004), dan teori trust atau kepercayaan dari McAllister (1995) yang kemudian dihubungkan dengan kinerja karyawan menurut Ivancevich (2001) seperti yang dapat dilihat di Gambar 1.

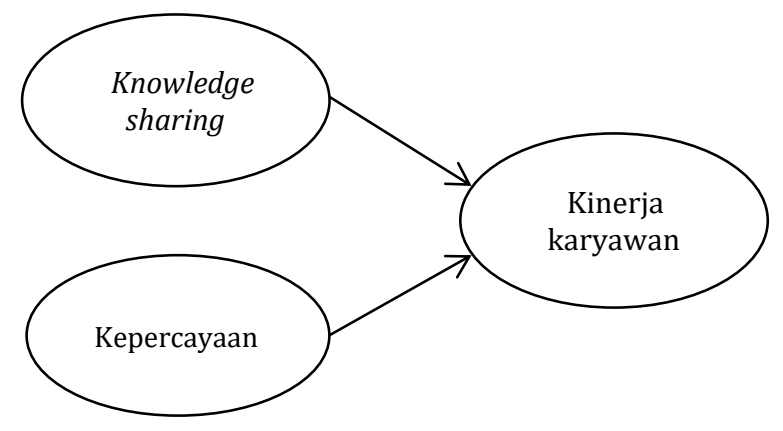

Gambar 1. Model Penelitian

\section{Metodologi}

Penelitian ini adalah penelitian explanatory untuk melihat pengaruh satu variabel terhadap variabel lain. Data dianalisis menggunakan regresi linear berganda untuk mengetahui pengaruh tiap variabel independen terhadap variabel dependen.

Jumlah populasi penelitian adalah 42 orang yang merupakan seluruh pegawai di PT. Tunas Dwipa Mitra Cabang Kepahiang. Sampel penelitian terdiri dari 40 orang staf dan manajer. 2 orang pegawai yang tidak dijadikan responden adalah manajer puncak (top manager) dan wakilnya. Jenis data dalam penelitian ini adalah data primer yang dikumpulkan menggunakan instrumen kuesioner. Jawaban responden terhadap variabel penelitian menggunakan skala Likert dengan skor 1-5, dengan kriteria: jawaban sangat tidak setuju diberi skor 1; jawaban tidak setuju diberi skor 2; jawaban cukup setuju diberi skor 3; jawaban setuju diberi skor 4; dan jawaban sangat setuju diberi skor 5. Sebelum disebarkan, data kuesioner telah diuji validitas dan reliabilitasnya terlebih dahulu sebelum digunakan dalam analisis lebih lanjut.

Untuk mengukur valid tidaknya kuesioner, maka dilakukanlah uji validitas dan realibilitas. Hasil uji validitas menunjukkan seluruh pertanyaan adalah valid. Hasil uji reliabilitas juga menunjukkan bahwa seluruh variabel penelitian adalah reliabel. Hal ini dibuktikan dengan nilai Cronbach's alpha seluruh variabel penelitian lebih besar dari 0,60 .

\section{Hasil dan Pembahasan}

Berdasarkan kuesioner yang telah diisi responden, maka dapat diketahui karakteristik responden sebagaimana terangkum pada Tabel 1. Mayoritas reponden berjenis kelamin laki-laki, berpendidikan S1 dengan usia 25-30 tahun, lama bekerja 2-5 tahun dengan posisi/jabatan sebagai supervisor.

Hasil regresi menunjukkan adanya pengaruh positif dan signifikan knowledge sharing dan kepercayaan terhadap kinerja karyawan. Hal ini berarti bahwa jika aktivitas knowledge sharing (X1) meningkat, maka kinerja karyawan akan meningkat, dan jika kepercayaan karyawan (X2) ditingkatkan, maka kinerja karyawan juga akan meningkat. Nilai koefisien determinasi berganda $\left(\mathrm{R}^{2}\right)$ sebesar 0,978 yang berarti bahwa variasi peningkatan atau penurunan kinerja karyawan PT. Tunas Dwipa Matra Kepahiang dapat dijelaskan oleh knowledge sharing dan kepercayaan dapat memberikan kontribusi sebesar $97,8 \%$. Sedangkan sisanya 2,2\% dipengaruhi oleh faktor lain di luar penelitian. Hasil ini memberikan makna bahwa variabel independen (knowledge sharing dan kepercayaan) memiliki 
kemampuan dalam menjelaskan variasi peningkatan atau penurunan kinerja.

\section{Tabel 1. Karakteristik Responden}

\begin{tabular}{lcc}
\hline $\begin{array}{l}\text { Karakteristik } \\
\text { Umur }\end{array}$ & Jumlah & Persentase (\%) \\
$\quad<25$ tahun & 5 & 12,5 \\
$>25-30$ tahun & 24 & 60,0 \\
$\quad>30$ tahun & 11 & 27,5 \\
Tingkat pendidikan & & \\
$\quad$ SLTA/SMU & 10 & 25 \\
Diploma & 7 & 17,5 \\
Sarjana (S1) & 23 & 57,5 \\
Jenis kelamin & & \\
Laki-laki & 24 & 60,0 \\
Perempuan & 16 & 40,0 \\
Lama bekerja & & \\
$\quad<2$ tahun & 5 & 12,5 \\
$>2-5$ tahun & 24 & 60,0 \\
$\quad>5$ tahun & 11 & 27,5 \\
Posisi/jabatan & & \\
Manajer & 5 & 12,5 \\
Supervisor & 20 & 50,0 \\
Staf & 15 & 37,5 \\
Jumlah responden & 40 & 100 \\
\hline Sumbr:pengolahan data &
\end{tabular}

Sumber: pengolahan data

Hasil pengolahan data penelitian melalui analisis regresi linear berganda dapat dilihat pada Tabel 2 berikut:

Tabel 2. Hasil Analisis Regresi

\begin{tabular}{cccccc}
\hline Variabel & Koef. & $\begin{array}{c}\text { Nilai Koef. } \\
\text { (Standardize })\end{array}$ & $\begin{array}{c}\text { Standard } \\
\text { Error }\end{array}$ & t-test & Sig. \\
\hline $\begin{array}{c}\text { Knowledge } \\
\text { sharing }\end{array}$ & b 1 & 0,874 & 0,047 & 23,372 & 0,000 \\
$\begin{array}{c}\text { Kepercayaan } \\
\text { R }\end{array}$ & b 2 & 0,146 & 0,063 & 3,899 & 0,000 \\
F-hitung & & $\begin{array}{c}0,978 \\
830,443\end{array}$ & & & 0,000 \\
\hline Sig.
\end{tabular}

Sig. 0,05.

Sumber: pengolahan data

Berdasarkan hasil perhitungan regresi, persamaan regresi yang diperoleh adalah sebagai berikut:

$$
\mathrm{Y}=0,874 \mathrm{X} 1+0,1468 \mathrm{X} 2
$$

Pengaruh Knowledge Sharing terhadap Kinerja Karyawan

Dari hasil analisis diketahui bahwa secara umum knowledge sharing PT. Tunas Dwipa Matra Kepahiang berjalan dengan baik. Hasil ini bermakna bahwa sharing atau berbagi pengetahuan yang dilakukan oleh karyawan kepada rekan kerjanya telah mampu mendorong karyawan yang lain untuk mencapai kinerja yang tinggi. Hal ini tentu saja akan mendorong pencapaian kinerja perusahaan secara umum. Oleh karena itu, kebiasaan berbagi pengetahuan diantara karyawan harus semakin ditingkatkan agar informasi mengenai perkembangan dari lingkungan luar maupun dari dalam dapat tersebar menyeluruh ke seluruh bagian dan tingkatan di dalam PT. Tunas Dwipa Matra Kepahiang, dengan demikian pengetahuan yang dimiliki dari setiap karyawan tidak terpendam di dalam diri masing-masing karyawan. Dengan adanya kebiasaan berbagi pengetahuan, maka karyawan dapat saling berbagi informasi, pengalaman, pengetahuan dan wawasan kepada seluruh karyawan PT. Tunas Dwipa Matra Kepahiang.

Hasil penelitian ini sejalan dengan penelitian yang dilakukan oleh Chen dan Chen (2011), Ohiorenoya (2015), dan Memah et al (2017) yang memberikan bukti bahwa knowledge sharing memiliki dampak atau pengaruh positifi terhadap kinerja karyawan. Disamping meningkatkan kinerja, knowledge sharing juga dapat membantu para karyawan untuk menyelesaikan masalah-masalah yang pelik di dalam pekerjaannya sehari-hari (Tobing, 2007)

\section{Pengaruh Kepercayaan terhadap Kinerja Karyawan}

Berdasarkan hasil analisis data diketahui bahwa kepercayaan berpengaruh positif dan signifikan terhadap kinerja karyawan. Hasil ini bermakna jika kepercayaan diantara karyawan meningkat, akan dapat meningkatkan kinerja karyawan. Tanggapan responden terhadap variabel kepercayaan menunjukkan bahwa karyawan PT. Tunas Dwipa Matra Kepahiang telah memberikan rasa kepercayaan yang tinggi baik kepada rekan kerja maupun manajemen perusahaan.

Hasil penelitian ini sejalan dengan penelitian yang dilakukan oleh Setyaningsih (2003) yang membuktikan bahwa kepercayaan berpengaruh positif terhadap kinerja karyawan. Kepercayaan merupakan keyakinan seorang karyawan terhadap rekan kerjanya yang diyakini akan melakukan halhal yang positif terhadap dirinya (Evans, 2003). Kepercayaan mempengaruhi seluruh hubungan antara individu dengan kelompok individu, dan merupakan kunci bagi kinerja 
organisasi karena kepercayaan memungkinkan kerjasama yang bersifat sukarela (Mathis dan Jackson, 2006).

\section{Kesimpulan}

Berdasarkan hasil penelitian dan pembahasan, maka dapat diambil kesimpulan bahwa knowledge sharing berpengaruh positif terhadap kinerja karyawan PT. Tunas Dwipa Matra Kepahiang. Artinya, jika knowledge sharing semakin meningkat maka kinerja karyawan akan meningkat. Kepercayaan berpengaruh positif terhadap kinerja karyawan PT. Tunas Dwipa Matra Kepahiang. Artinya, jika kepercayaan semakin meningkat, maka kinerja karyawan akan meningkat.

\section{Saran}

Berdasarkan kesimpulan penelitian, maka saran yang dapat diberikan bagi perusahaan adalah agar perusahaan dapat terus meningkatkan aktivitas knowledge sharing karyawan berkenaan dengan prosedur dan pembagian tugas yang jelas. Upaya ini dilakukan dengan adanya informasi yang berimbang mengenai prosedur dan pembagian tugas tersebut, sehingga akan meningkatkan efektivitas kerja dan kinerja karyawan. Antar karyawan harus menjalin hubungan kerjasama dengan dasar saling percaya. Hal tersebut dapat dilakukan melalui komunikasi yang terbuka antar karyawan dan manajemen, sehingga setiap karyawan merasakan diperlakukan secara adil oleh organisasi.

Penelitian ini terbatas pada jumlah sampel yang sangat kecil dan dilakukan hanya pada sebuah perusahaan. Untuk penelitian ke depan dapat dilakukan dengan jumlah sampel yang lebih besar pada level industri agar generalisasi hasil penelitian menjadi lebih baik.

\section{Daftar Referensi}

Brown, Sarah, Gray Daniel, McHardy Jolian and Taylor Karl. 2015. Employee trust and workplace performance. Journal of Economic Behavior \& Organization, 116: 361-378.

de Jong, Bart, Gillespie, Nicole, and Kurt T, Dirks. 2016. Trust and Team Performance: A MetaAnalysis of Main Effects, Moderators and Covariates. Journal of Applied Psychology, (April).

De Vries, Reinout E. van den Hooff, and Bart, de Ridder, Jan A. 2006. Explaining Knowledge Sharing: The Role of Team Communication Styles, Job Satisfaction, and Performance Beliefs. Communication Research. Apr, Vol. 33 (2): 115-135.

Chen, Shun-Yu and Li-Ju Chen. 2011. Capital structure determinant: An empirical study in Taiwan, African Journal of Business Management, Vol. 5(27): 10974-10983.

Colquitt, J. A., Scott, B. A., and LePine, J. A. 2007. Trust, Trustworthiness, and Trust propensity: a meta analytic test of their unique relationships with rist taking and job performance. The Journal of Applied Psychology, Vol. 92 (4).

Evans, James R. 2003. Total Quality (Management, Organization and Strategy). Ohio: SouthWestern.

Hooff, Bart van den and de Ridder, Jan. A. 2004. Knowlegde sharing in context: the influence of organizational commitment, communication climate, and CMC use on knowledhe sharing. Journal of Knowledge Management, Vol 8 (6): 117-130.

Ivancevich, John M. 2001. Human Resource Management, Eight Edition. New York: McGraw Hill.

Mathis, R. L. and J. H. Jackson. 2006. Human Resource Management: Manajemen Sumber Daya Manusia. Jakarta: Salemba Empat.

Memah, Leonardo, Pio, Riane, Jhonly., dan Kaparang, Sonny, Gerson. 2017. Pengaruh Knowledge Sharing terhadap Kinerja Karyawan Kantor Perwakilan Bank Indonesia di Provinsi Sulawesi Utara. Jurnal Administrasi Bisnis, Vol. 5 (2): 1-9.

McAllister, Daniel, J. 1995. Affect-and CognitionBased Trust as Foundations for Interpersonal Cooperation in Organizations. The Academy of Management Journal, Vol. 31 (1): 24-59. 
Ohiorenoya, John Omogeafe. 2015. Knowledge sharing and performance in the oil and gas industry. Journal of Information \& Knowledge Management. Vol. V (iii): 82-90

Setyaningsih, Wesiati. 2003. Pengaruh Kepercayaan pada Atasan, Kepuasan Kerja dan Komitmen Organisasi terhadap Kinerja Karyawan (Studi Kasus Pada Pegawai Pemkot Semarang). Tesis. Univesitas Diponegoro.

Setiarso, Bambang. 2009. Penerapan Knowledge Management Pada Organisasi. Yogyakarta: Graha Ilmu.

Tobing, Paul L. 2007. Knowledge Management: Konsep Arsitektur dan Implementasi. Yogyakarta: Graha Ilmu.

Wang, Y. M. 2006. Measuring KMS Success: A Respecification of the DeLone and McLean Model. Information \& Management, 43 (6): 728- 739 .

Yusup, Pawit M. 2012. Perspektif Manajemen Pengetahuan Informasi, Komunikasi, Pendidikan, dan Perpustakaan. Jakarta: Rajawali Press. 